\title{
Reflexões e conselhos sobre tipografia
}

\author{
Reflections and advices on typography
}

Regina Wilke $^{1}$

${ }^{1}$ Centro Universitário Senac - Senac SP

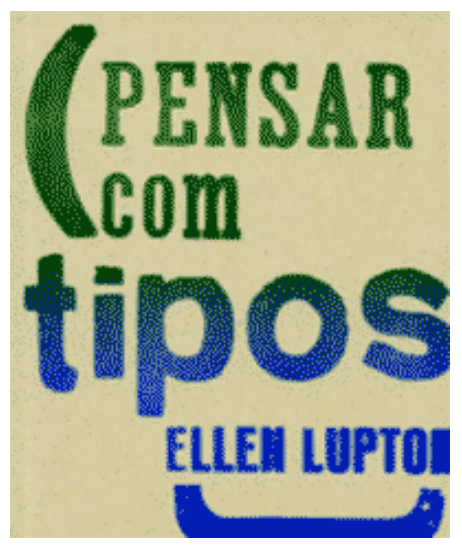

LUPTON, Ellen. Pensar com tipos: guia para designers, escritores, editores e estudantes. Thinking with type: a critical guide for designers, writers, editors \& students. Tradução: André Stolarski. São Paulo: CosacNaify, 2006. $184 p$ [ISBN $85-7503-553-3$ ]

\section{Resumo da obra}

A obra é um conciso manual de tipografia e sua aplicação, uma referência para estudantes de design. O volume é estruturado em três partes, Letra, Texto e Diagrama (no original, grid). Nesta seqüência explora a forma básica das letras, a construção das palavras, a organização de massas de textos em diagramas racionalistas e sistemas flexíveis. Cada ensaio traz um panorama dos aspectos históricos, tecnológicos e teorias, complementado com exemplos práticos, trabalhos concebidos por reconhecidos designers gráficos. Complementa o livro uma seção de conselhos práticos, incluindo informações sobre uso de traços, espaços e pontuação, e um pequeno guia de edição, preparação de originais e revisão de provas para designers. Na versão brasileira, este apêndice original é intitulado "Dicas Úteis", e há uma última seção, intitulada "Apêndice", com traduções complementares, bibliografia, índice onomástico e informações sobre a autora.

\section{Summary of the book}

The book is a concise manual of typography and its applications, a reference to students of design. The publication is divided into three parts: Letter, Text and Grid (translated as diagrama, or diagram, in the Brazilian version). In this sequence, it explores the basic form of letters, the construction of words, the flexible organization of text in rational diagrams and systems. Each essay brings an overview of the historical and technological aspects, and theories, complemented with practical examples of works by recognized graphic designers. The book is complemented by a section with practical advice, including information on the use of dashes, spaces and punctuation, and a short guide to editing and proofreading for designers. In the Brazilian version, this original "Appendix" is entitled "Dicas Úteis" (Useful Tips), and there is a different "Appendix", with complementary translations, bibliography, index and information about the author.

Ellen Lupton, é designer gráfica, educadora e renomada autora. Entre seus diversos livros publicados, destacam-se: Design It Yourself (2006), Skin: Surface, Substance + Design (2002), Graphic Design in the Mechanical Age (1999), Mixing Messages (1996). É coordenadora do programa de Mestrado em design gráfico do Maryland Institute College of Art (MICA), em Baltimore, e curadora de design contemporâneo no Cooper-Hewitt National Design Museum em Nova lorque.

Na apresentação de "Pensar com tipos", Lupton ressalta que este livro não trata a tipografia como um fim em si mesmo, mas "como uma ferramenta com a qual o conteúdo ganha forma, a 
linguagem ganha um corpo físico e as mensagens ganham um fluxo social” (Lupton, 2006: 8). Para concretizar este objetivo, este manual, elaborado pra acompanhar o curso de tipografia ministrado pela autora, aborda práticas e teorias contextualizando-as em seu universo histórico, desde os primórdios da imprensa até a situação criada pelos dos novos meios de comunicação. Apresenta parâmetros para a seleção e uso eficaz da tipografia em materiais impressos e em meios eletrônicos.

O projeto gráfico e editorial do livro propõem um diálogo constante entre o texto e complementos informacionais, dispostos em seu entorno. Imagens ilustrativas, bibliografias importantes sobre o assunto e notas marginais acompanham o texto principal, favorecem sua compreensão e direcionam para leituras especificas.

Ao final, apresenta um guia de edição e preparação de originais no papel e no computador e um de revisão de provas para designers. No apêndice da publicação acrescenta uma farta bibliografia complementar. Acompanha o lançamento do livro o website $<$ http://www.thinkingwithtype.com/> com uma seção adicional para professores. O livro, como apontamos, expõem seu conteúdo de diferentes maneiras para o leitor compartilhar das informações.

A tipografia é um dos elementos fundamentais do design editorial. É a partir do desenvolvimento dos aspectos tipográficos, formais e estruturais que se estabelecem as estratégias para publicação e transmissão da informação. A relevância desta obra está justamente em focar estas três dimensões.

O primeiro tema, letra, expõe aspectos documentais da produção de fontes e sua evolução, estabelece que a história da tipografia reflete as tensões criadas pela oposição mão e máquina, orgânico e geométrico, o corpo humano e o sistema abstrato (Lupton, 2005: 13). Apresenta uma biblioteca de tipos, do século XV até o presente, concebidos pelos tipógrafos mais importantes, cuja concepção foi norteada pelas expectativas dos autores e pelo espírito da época.

Lupton defende que é o conhecimento da história dos tipos e suas conotações atuais, mais as suas qualidades formais associadas à situação social específica, e massa de conteúdo que definem a seleção da tipografia e sua aplicação no projeto. Traça assim a base para se pensar com tipos.

Prossegue com explicações técnicas e estéticas que envolvem a anatomia do tipo; apresenta os princípios geradores do sistema básico de classificação dos tipos, e algumas famílias com seu conjunto de variações, apontando a diversidade de possibilidades da construção deste sistema.

Para finalizar a abordagem específica sobre o assunto "letra", mostra as fontes bitmaps feitas de pixels. Propõem um exercício de construção de fonte sobre uma malha quadrada, com o uso de elementos retilíneos, uma provocação instigante que traça um paralelo entre a estrutura das tecnologias digitais e os experimentos das vanguardas dos anos 1910 e 1920.

O texto desta primeira etapa traz informações relevantes, mas de forma concisa, úteis para a escolha da tipografia adequada em diferentes mídias atendendo a função da peça e públicos específicos.

O segundo tema versa sobre o texto, mais especificamente trata da questão entre texto e espaço, assim como do tratamento dado ao texto nas diferentes mídias, demarcando a evolução da página linear à tela não linear.

A discussão gira em torno de que muitos projetos de design pedem mais ênfase no espaço, no sistema e na estrutura simultânea do que na seqüência e na afirmação de uma narrativa linear. A palavra, por sua vez, é vista como um objeto localizado no espaço. Cita Jacques Derrida, para quem a tipografia manipula as áreas silenciosas do alfabeto. Deste modo, grafar um texto é um ato de marcar e de espaçar. E a tipografia é que auxilia os leitores a percorrerem o conteúdo.

É dentro deste contexto que ocorre a argumentação, a autora busca entender as teorias que encadeiam estas questões. Destaca a visão de Roland Barthes que declara que o texto é 
inteiramente tecido por citações, fragmentos de linguagens culturais e, portanto constata que a sua metáfora é a rede. Uma rede aberta de referências, onde o leitor contribui na construção do significado.

Aproxima o foco para o contexto atual, discorre sobre a base de dados, a Internet, a produção de conteúdo para diferentes conceitos de página impressa e para mídias digitais, onde os conteúdos são mais interativos e multimídia, com seus gêneros que estabelecem um espaço informacional, mais que uma seqüência linear. Estabelece, então, a base para a tônica deste tópico, o uso sofisticado do espaço, vinculado à liberação da linearidade.

Ainda apoiada no modelo de Barthes, ressalta a importância do leitor como intérprete final do texto e o fato da tipografia ser entendida como "discurso". Assim, a linguagem tipográfica se revela em diferentes níveis de significação e estabelece, em paralelo a isto, um campo para experimentação.

Apresenta o trabalho de Katherine McCoy, designer ligada a Academia de Cranbrook, que explorou a interseção entre teoria pós-estruturalista e prática de design, desafiando os leitores a produzirem seus próprios significados, ressaltando a participação dos designers no processo autoral, sugerindo o designer como co-autor do projeto.

Por fim, aproximando-se da década de 90, cita estudos de interação entre homem-computador, design de interface e de usabilidade, que apontam o usuário como o sujeito dominante do processo, descaracterizando o papel do designer como co-autor do projeto. Aponta a necessidade dos designers conhecerem teorias de interatividade para entender os novos hábitos culturais impostos pela tela, lembra ainda da dissolução da escrita, própria a Internet, pela natureza dos conteúdos e sua busca, onde leitores valorizam a função em detrimento da forma. A informação teórica vem propiciar ou validar procedimentos práticos, e a autora demonstra esta interação através de atitudes de designers e exemplos.

Após as questões conceituais, a obra, com clareza e consistência, prossegue tratando a tipografia e sua construção no espaço em seus aspectos técnicos, kerning, espacejamento, entrelinhamento, alinhamento, hierarquia em documento impresso e na internet, pela disposição espacial ou gráfica, e por fim a acessibilidade na internet. Finaliza com exercícios sobre parágrafos, palavras e textos propondo uma pequena vivência dos conceitos tratados.

O terceiro tema é diagrama, recurso do design gráfico que contribui para estruturar a comunicação, visto como a infra-estrutura da tipografia. Aborda os diferentes tipos de estruturas baseadas em colunas e grids, sistemas para a disposição de conteúdos em páginas, telas, enfim, em ambientes construídos.

$\mathrm{Na}$ linha da história inicia com os layouts de livros, com a supremacia da página-moldura e a mancha gráfica composta pelo bloco sólido do texto, cita ainda os layouts alternativos, como o diagrama de duas colunas da Bíblia de Gutenberg. Aponta para o questionamento da sintaxe tradicional de impressão postulado por Marinetti. Apresenta El Lissitsky, construtivista que entendia a página como um espaço que se estende além das margens e adotava o uso de réguas para dividi-lo. Complementa com os designers holandeses, do grupo De Stijl, que migraram o diagrama da tela de pintura para o design da página.

Por fim evidencia o conceito de design defendido por Jan Tchichold, um meio disciplinador e ordenador, e sua proposta de sistema modular. Expõem o método de organização que deriva do Estilo Internacional, vertente suíça do design, baseada no desenvolvimento e na aplicação de sistemas que visam uma organização racional do espaço, citando seus representantes Max Bill, Karl Gerstner, Emil Ruder e Josef Muller-Brookmann e seus diagramas modulares.

Lupton, na organização do espaço, filia-se ao paradigma funcionalista, anuncia a preferência por sistemas geométricos de gride, apresenta mas não valida o pluralismo expressivo no panorama gráfico, não se compraz com as transgressões. Comenta sobre a vertente norteamericana, baseada no insight, que concebeu estilos velozmente mutantes, entre elas experiências de design que trabalhavam com a complexidade e a dramatização das possibilidades formais do projeto. Contudo, logo a seguir, ressalta que o pensamento programático ressurge com 


\section{Infodesıgn}

força para atender projetos de informação e a Internet reascendeu o interesse pelo pensamento universal do design.

Para explicar este argumento, prossegue dedicando parte deste tópico a web. Neste ponto assinala que a tabela, um corolário do gride, é uma ferramenta cognitiva. Acrescenta que esta foi incorporada ao HTML, linguagem de marcação empregada para produzir páginas na Web, porém a tabela teve seu uso transgredido pelos designers, que a aproveitaram como diagramas tipográficos, para controlar posicionamentos de imagens e legendas, por exemplo. Menciona que este procedimento pode prejudicar o acesso de usuários cegos, que contam com dispositivos para traduzir as página digitais em som, célula a célula, linha a linha. Apesar de levantar o problema da acessibilidade, não prossegue a discussão. Passa para uso do Flash, software de gráfico vetorial, que suporta imagens bitmap e vídeos em website, reconhecendo que são mais cinemáticos que tipográficos.

Conclui que o diagrama é um instrumento poderoso, e que atualmente "um segundo modernismo emergiu, revigorando a busca de formas utópicas do design universal, que marcou o design como discurso e disciplina há um século" (Lupton, 2005: 134).

O livro, bem estruturado, fornece bases teóricas e instrumentais para a utilização da tipografia, com foco no design da informação.

\section{Sobre a autora}

\section{Regina Cunha Wilke}

Formada em Arquitetura e Urbanismo pela Universidade de São Paulo, graduação (1975), mestrado (1998) e doutorado (2004). Atualmente é coordenadora da pós-graduação lato sensu em design gráfico do Centro Universitário Senac. Leciona e orienta na graduação e na pós-graduação em design do Centro Universitário Senac, é professora titular da Fundação Armando Álvares Penteado. Coordena o projeto de pesquisa "O processo cultural do design: acervo de cartazes" do Grupo de Pesquisa em Tipografia e Linguagem Gráfica do Centro Universitário Senac.

regina.cwilke@sp.senac.br 